Article

\title{
Catalase and Ascorbate Peroxidase in Euglenozoan Protists
}

\author{
Ingrid Škodová-Sveráková ${ }^{1,2, *,+}$ @, Kristína Záhonová ${ }^{1,3,+} \mathbb{\oplus}$, Barbora Bučková ${ }^{2}$, \\ Zoltán Füssy ${ }^{3}\left[\right.$, Vyacheslav Yurchenko ${ }^{4,5}$ and Julius Lukeš ${ }^{1,6, *(1)}$ \\ 1 Institute of Parasitology, Biology Centre, Czech Academy of Sciences, \\ 37005 České Budějovice (Budweis), Czech Republic; kika.zahonova@gmail.com \\ 2 Faculty of Natural Sciences, Comenius University, 84104 Bratislava, Slovakia; barbora@bucko.sk \\ 3 Faculty of Science, Charles University, BIOCEV, 12800 Prague, Czech Republic; zoltan.fussy@gmail.com \\ 4 Life Science Research Centre, Faculty of Science, University of Ostrava, 71000 Ostrava, Czech Republic; \\ vyacheslav.yurchenko@osu.cz \\ 5 Martsinovsky Institute of Medical Parasitology, Tropical and Vector Borne Diseases, Sechenov University, \\ 119435 Moscow, Russia \\ 6 Faculty of Sciences, University of South Bohemia, 37005 České Budějovice (Budweis), Czech Republic \\ * Correspondence: skodovaister@gmail.com (I.Š.-S.); jula@paru.cas.cz (J.L.) \\ $\dagger$ These authors contributed equally to this work.
}

Received: 27 March 2020; Accepted: 22 April 2020; Published: 24 April 2020

\begin{abstract}
In this work, we studied the biochemical properties and evolutionary histories of catalase (CAT) and ascorbate peroxidase (APX), two central enzymes of reactive oxygen species detoxification, across the highly diverse clade Eugenozoa. This clade encompasses free-living phototrophic and heterotrophic flagellates, as well as obligate parasites of insects, vertebrates, and plants. We present evidence of several independent acquisitions of CAT by horizontal gene transfers and evolutionary novelties associated with the APX presence. We posit that Euglenozoa recruit these detoxifying enzymes for specific molecular tasks, such as photosynthesis in euglenids and membrane-bound peroxidase activity in kinetoplastids and some diplonemids.
\end{abstract}

Keywords: Euglenozoa; ascorbate peroxidase; catalase; enzymatic activity; phylogeny

\section{Introduction}

Aerobic metabolism is associated with the undesirable production of reactive oxygen species (ROS) due to the leakage of electrons to molecular oxygen [1]. The ROS molecules include free radicals, such as superoxide anion $\left(\mathrm{O}_{2}{ }^{\bullet-}\right)$ or hydroxyl radical $\left({ }^{\bullet} \mathrm{OH}\right)$, and non-radical molecules, e.g., hydrogen peroxide $\left(\mathrm{H}_{2} \mathrm{O}_{2}\right)$ [2]. In the eukaryotic cell, respiration in mitochondria and photosynthesis in plastids are the main ROS producers. However, ROS may accumulate as a by-product in any cell compartment where aerobic metabolism occurs. While molecular oxygen shows relatively low reactivity towards most cellular components, its partially reduced forms are much more reactive. Oxidative damage of proteins, lipids, and nucleic acids happens when the level of ROS exceeds the physiological threshold under oxidative stress conditions [3]. Hydrogen peroxide is often used as a second messenger in cell signaling pathways and its accumulation has long been documented to play an important role in mediating programmed cell death—apoptosis or (at very high concentrations) necrosis [4]. Hence, both the production and removal of ROS must be strictly controlled. This is why enzymatic and non-enzymatic mechanisms for ROS detoxification are employed by virtually every cell [5].

The family of enzymatic antioxidants comprises catalase (CAT), ascorbate peroxidase (APX), superoxide dismutase (SOD), glutathione peroxidase (GPX), and peroxiredoxin (PrxR) [6-8]. Both CAT 
and APX are heme-containing enzymes widely distributed among aerobes. As such, the APX activity was documented in higher plants and a range of protist lineages, including chlorophytes, rhodophytes, stramenopiles, and euglenozoans [9-11]. The structure and function of APX have been well described in plants, which usually carry several isoforms [12]. While APX requires ascorbate for ROS detoxification, with four reactions of the ascorbate-glutathione cycle necessary for ascorbate regeneration, CAT represents a system for direct ROS dissociation by conversion of $\mathrm{H}_{2} \mathrm{O}_{2}$ molecules into water and molecular oxygen. This enzyme requires one molecule of $\mathrm{H}_{2} \mathrm{O}_{2}$ to bind at the CAT active site in order to generate a reaction intermediate that binds the second molecule of $\mathrm{H}_{2} \mathrm{O}_{2}$ [13]. The affinities of APX and CAT for $\mathrm{H}_{2} \mathrm{O}_{2}$ are in $\mu \mathrm{M}$ and mM ranges, respectively, reflecting that they belong to two fundamentally different classes of peroxidases [14]. Having a low affinity to $\mathrm{H}_{2} \mathrm{O}_{2}$, CAT is most effective at high concentrations of peroxide [15].

ROS scavenging systems are classified according to their subcellular localization, which is primarily determined by the organelle-specific targeting signals found in the $\mathrm{N}$ - and C-termini of the corresponding proteins. Soluble forms are found in the cytosol, mitochondria, and plastids, while membrane-bound isoforms are found in microbodies (including peroxisomes and glyoxysomes) and plastid thylakoids [16-18]. Usually, multiple systems are present in a given cellular compartment and cooperate to scavenge for ROS [19]. CAT occurs in either soluble or membrane-bound forms, and is typically localized in the peroxisomes and mitochondria, where $\mathrm{H}_{2} \mathrm{O}_{2}$ production is most significant [20].

Kinetoplastids and euglenids possess yet another mechanism for scavenging ROS centered on the glutathione analog trypanothione, that is unique to these protists [21]. The trypanothione system reduces $\mathrm{H}_{2} \mathrm{O}_{2}$ via tryparedoxin and tryparedoxin peroxidase. Since CAT and the selenium-containing GPX are absent in the kinetoplastid flagellates (for exceptions, see below), trypanothione is particularly important in this group of organisms [22]. For the same reasons, APX appears to be a key enzyme for redox homeostasis in these flagellates [23]. In addition, trypanosomatids also lack the whole thioredoxin/thioredoxin reductase pathway, and it was proposed that trypanothione actually substitutes it. However, in the absence of CAT, trypanothione and thioredoxin systems co-exist in Euglena gracilis, indicating that these systems are not entirely redundant [24-26].

It was shown that, under stress, plants boost the activity of all of their ROS scavenging enzymatic systems, namely CAT, APX, SOD, GPX, and PrxR [16]. Interestingly, an increase in the APX activity can compensate for the loss of the CAT activity in plants and prevent the accumulation of intracellular ROS, suggesting the functional overlap of both systems [5]. Indeed, in tobacco, the CAT and APX machineries are (to some extent) functionally redundant, as one can compensate for the lack of another [27]. Given the complex pattern of antioxidant systems in the euglenozoan protists, we performed detailed phylogenetic and functional analyses of their APX proteins, dissected their co-occurrence with CAT, and identified multiple acquisitions of these nearly ubiquitous enzymes from unrelated sources.

Euglenozoa are as diverse as can be, and they comprise free-living, parasitic, and photosynthetic species, having clinical, economical, and environmental importance. Yet, how euglenozoans actually cope with ROS is still poorly understood. Given the complex pattern of antioxidant systems in euglenozoan protists, we performed phylogenetic and biochemical analyses of their APX and CAT to shed more light on the importance of these nearly ubiquitous enzymes.

\section{Results}

\subsection{Euglenozoans Encode Unique HPXs and CAT of Different Origins}

An extensive phylogenetic analysis of the APX domain-containing sequences revealed the subdivision of sequences derived from Euglenozoa into several clades (Figure 1; File S1). They are well-separated from heme (HPX) and cytochrome $c$ peroxidases (CCP), suggesting a sub-functionalization of the HPX superfamily early in the eukaryotic evolution. All studied sequences can be divided into the following clades: (i) diplonemid peroxidases, which are invariably predicted as mitochondrion-localized 
(in turquoise) (Supplementary Table S1), form a moderately supported sister lineage to mitochondrial CCPs; (ii) a sequence from the diplonemid Lacrimia lanifica forms a sister branch to the kinetoplastid-specific hybrid APX-CCP proteins (hAPX-CCPs, in blue). While the kinetoplastid hAPX-CCP orthologues carry a mitochondrial targeting signal, the L. lanifica sequence possesses a peroxisomal targeting signal (Supplementary Table S1), which should navigate the corresponding protein to the glycosomes [28]; (iii) APXs of the diplonemids Artemidia motanka, Namystynia karyoxenos, and Sulcionema specki are nested inside the plastid/cytosolic APX clade along with various algae, parasitic chytridiomycota, and filter-feeding choanoflagellates, all of which carry a PTS2 signal, strongly indicating their glycosomal localization (in bright orange); (iv) a clade, consisting solely of sequences from the diplonemids A. motanka and N. karyoxenos, branches inside the plastid hAPX-CCPs cluster, close to the plastid-targeted euglenid APX (in dark green). Consistent with the absence of plastid in diplonemids, their APXs are predicted to be cytosolic (Supplementary Table S1); (v) a small clade contains an additional APX homolog from the plastid-carrying euglenids, otherwise specific for Chloroplastida (in light green); (vi) all remaining 29 diplonemid and six euglenid sequences constitute five independent clades that are unrelated to known APX sequences (in black). In the absence of an appropriate reference ortholog, we cannot infer their function, and thus we denoted them as Euglenozoa-specific HPX. We predict these proteins to be targeted to a range of cellular compartments, including mitochondria, glycosomes, and the secretory organelles (Supplementary Table S1).

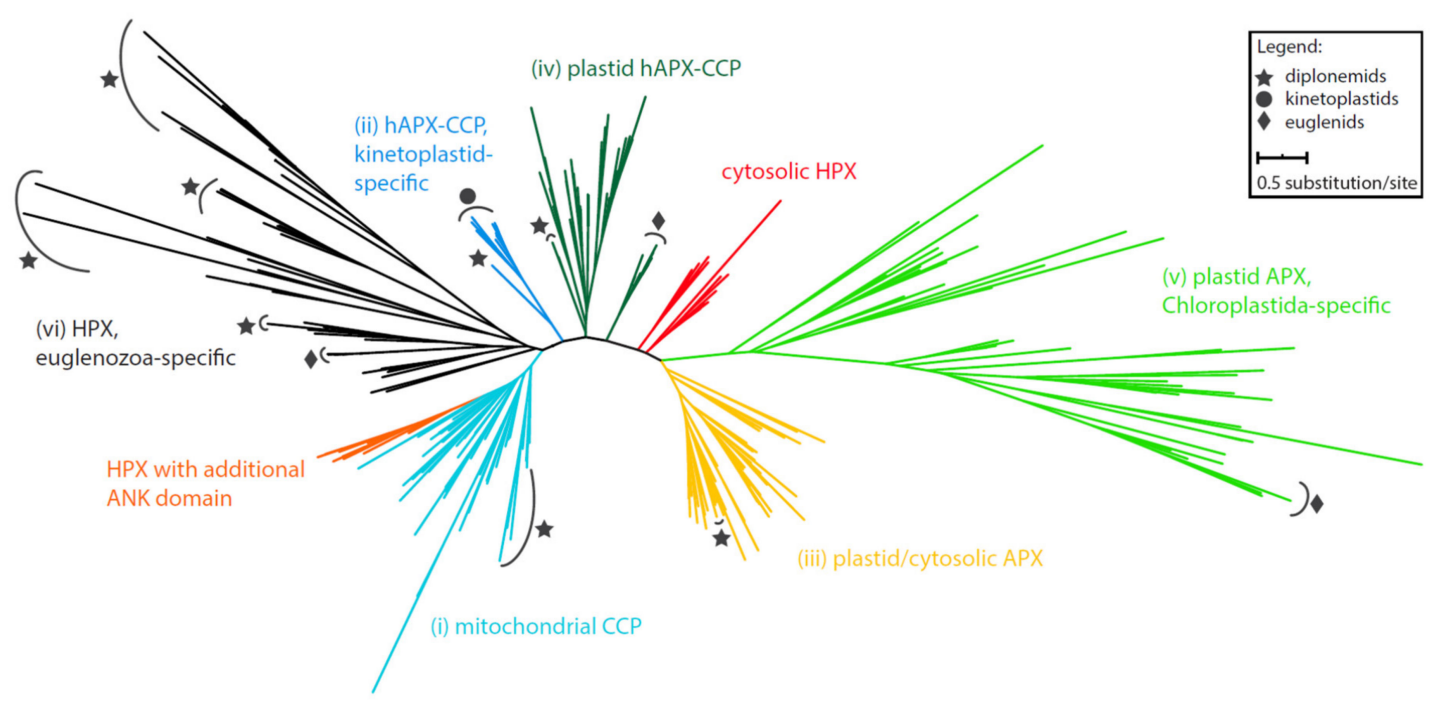

Figure 1. Maximum-likelihood phylogeny of heme peroxidases possessing APX domains in Euglenozoa. Taxa representing euglenozoan sequences are marked by symbols according to the graphical legend. Full tree in Newick format can be found in File S1.

It was previously shown that kinetoplastid flagellates acquired their CAT enzyme at least two times independently from bacteria. As revealed by the phylogenetic analysis, CAT of Leishmaniinae and the Blastocrithidia/"jaculum" clade derive from different bacterial groups [29,30], and this was confirmed here using a larger dataset (Figure 2A; File S2). While euglenids, studied so far, do not encode CAT [11,31], we wondered whether the same pattern applies to diplonemids, which constitute a sister clade to kinetoplastids [32,33]. For this purpose, we took advantage of the transcriptomic data derived from the axenic cultures of several diplonemid species [26]. As supported by maximum likelihood, the CAT sequences of Diplonema japonicum, N. karyoxenos, Rhynchopus humris, A. motanka, and $S$. specki are nested within eukaryotes with maximum support, consistent with the ancestral origin of their CAT (Figure 2B). However, yet another diplonemid, Diplonema papillatum, has apparently gained its CAT by horizontal gene transfer from an alpha-proteobacterium (Figure 2A,C). Hence, the inspected euglenozoans have acquired CAT from at least three distinct bacterial sources, while the genes of the majority of studied diplonemids are clearly of eukaryotic origin. This shows an unusual 
propensity of this group of protists to functionally replace CAT with homologs from bacteria that they likely prey upon.
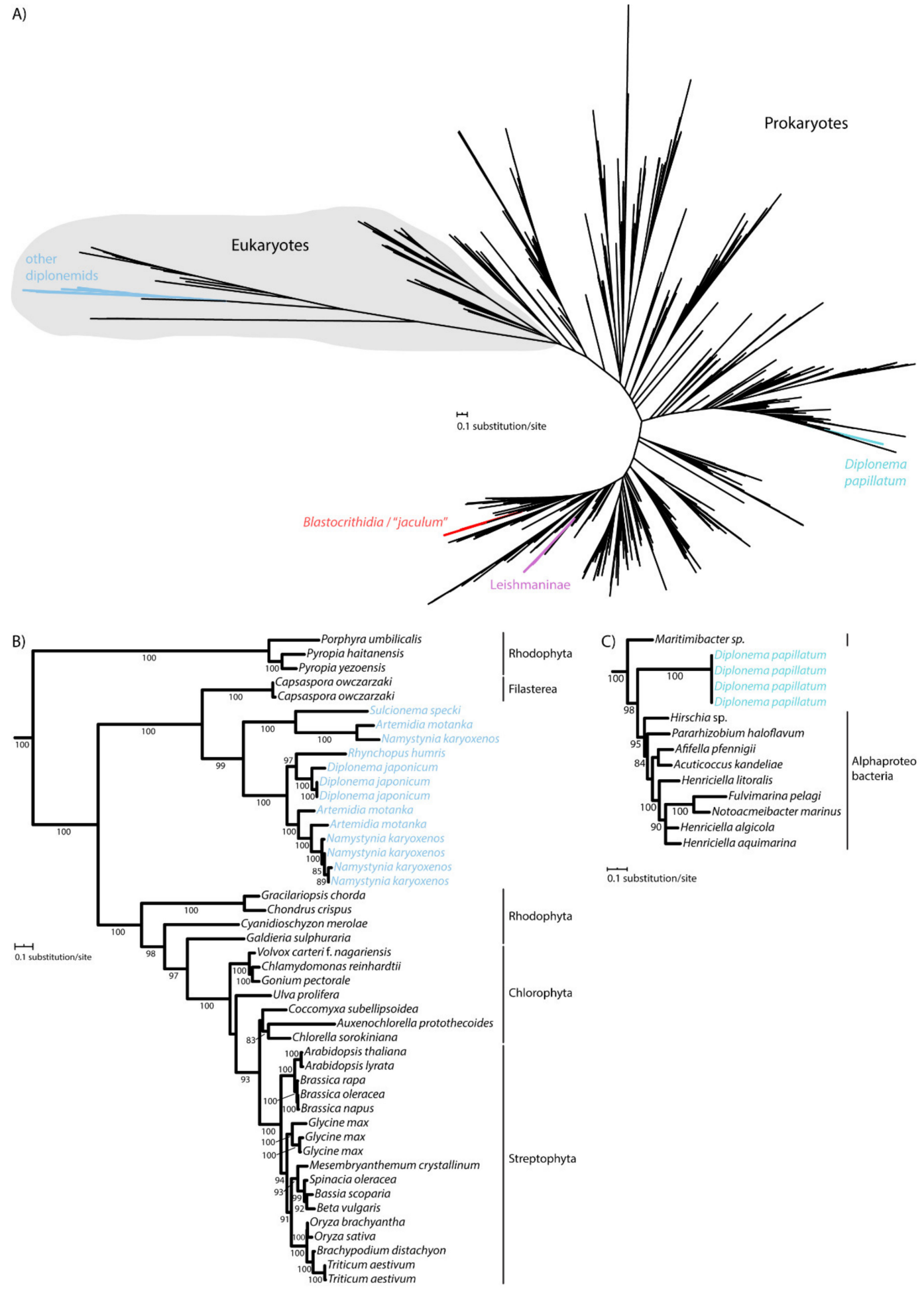

$\overleftrightarrow{0.1 \text { substitution/site }}$

Figure 2. Maximum-likelihood phylogeny of catalases in Euglenozoa. (A) Unrooted tree showing ancestral origin of diplonemid CAT branching within eukaryotes and three horizontal gene transfer events in Blastocrithidia/"jaculum", Leishmaninae and D. papillatum. Full tree in Newick format can be found in File S2. (B) Subtree showing the ancestral diplonemid CAT. (C) Subtree showing the D. papillatum CAT related to alpha-proteobacteria. UFBoot support values are shown when $\geq 80$. 


\subsection{APX Activity Widely Varies Among Species}

To corroborate computational results by biochemical evidence, we measured the CAT and APX activities separately in total cell lysates. In a good correlation, D. papillatum lacks both APX genes and the corresponding biochemical activity (Figure 3).
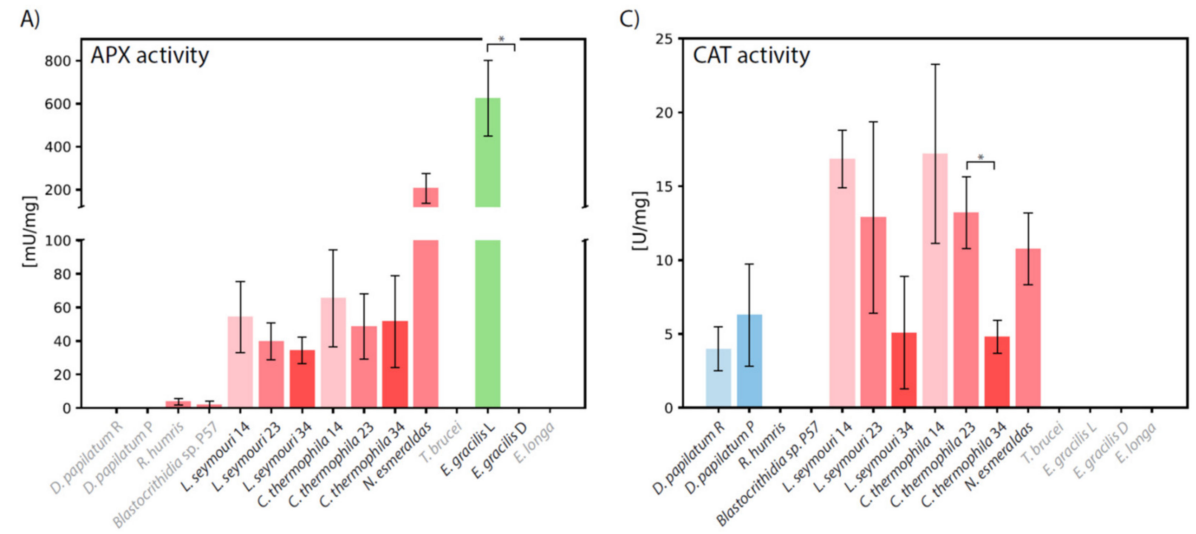

B)

D)
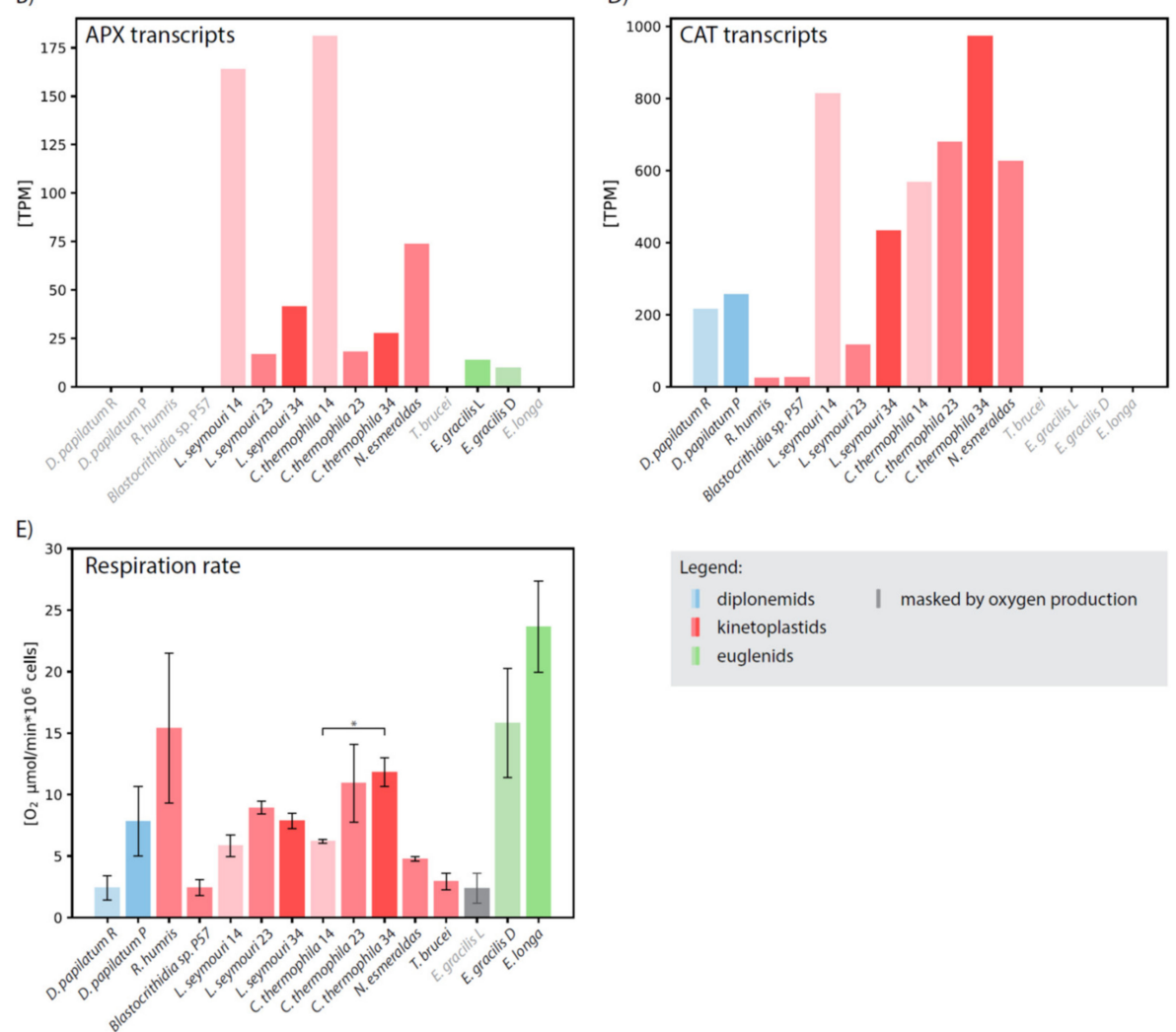

Figure 3. Biochemical and transcriptomic analysis. Comparison of (A) APX and (C) CAT activities, (B) APX and (D) CAT expression levels, and (E) oxygen uptake in Diplonema papillatum cultivated in nutrient-rich (R) and nutrient-poor (P) medium, Rhynchopus humris, Blastocrithidia sp. P57, Leptomonas seymouri cultivated at $14{ }^{\circ} \mathrm{C}(14), 23{ }^{\circ} \mathrm{C}(23)$ and $34{ }^{\circ} \mathrm{C}(34)$, Crithidia thermophila cultivated at $14{ }^{\circ} \mathrm{C}(14)$, $23{ }^{\circ} \mathrm{C}(23)$ and $34^{\circ} \mathrm{C}(34)$, Novymonas esmeraldas, Trypanosoma brucei, Euglena gracilis cultivated in light (L) and dark (D), and Euglena longa. Species names in grey denote organisms, in which corresponding enzyme was not identified. Activity $U$ is defined as the amount of the enzyme which catalyzes the conversion of $1 \mu \mathrm{mol}$ of ascorbate (APX) or $\mathrm{H}_{2} \mathrm{O}_{2}$ (CAT) per $1 \mathrm{~min}$. Each experiment was performed in two biological replicates. Statistical significance of differences between organisms was evaluated by an unpaired $t$-test. * statistically significant $(p<0.05)$. Note that respiration value in light-grown E. gracilis is masked by photosynthetic oxygen consumption (grey bar). 
Surprisingly, in R. humris and Blastocrithidia sp. P57 very low APX activity was detected, despite the fact that both species apparently lack the corresponding gene. Leptomonas seymouri, Crithidia thermophila (both cultivated at a standard temperature of $23^{\circ} \mathrm{C}$ ), and Novymonas esmeraldas possess the kinetoplastid-specific hAPX-CCP, and consistently, specific activities of $39 \pm 10,48 \pm 19$, and $206 \pm 69 \mathrm{mU} / \mathrm{mg}$, respectively, were documented in these species. (Figure 3A; Supplementary Table S2). It should be noted that the activity of $N$. esmeraldas APX is comparable to that of the full-length APX of Leishmania major [34]. Although the APX activity changed when L. seymouri and C. thermophila were shifted to $14{ }^{\circ} \mathrm{C}$ and $34{ }^{\circ} \mathrm{C}$, the limit temperatures at which both organisms are able to grow, the change was not statistically significant (Figure 3A). Interestingly, gene expression followed the same pattern in both species with the highest number of transcripts at $14{ }^{\circ} \mathrm{C}$ and their decrease with elevated temperature (Figure 3B; Supplementary Table S2).

When E. gracilis is grown under light conditions, promoting photosynthesis, it exhibits high APX activity of $625 \pm 176 \mathrm{mU} / \mathrm{mg}$ (Supplementary Table S2), which is still 4-times lower than the activity reported for the pea plastids [35]. When the E. gracilis culture was transferred from light to dark, its color changed from green to pale reddish and the photosynthetic activity ceased. Although a low amount of APX transcripts were still present in these conditions, the enzymatic activity dropped below the limit of detection (Figure 3B; Supplementary Table S2). Consistent with the localization of APX in the plastid, neither the dark-grown E. gracilis nor the non-photosynthetic Euglena longa exhibit any APX activity (Figure 3A,B; Supplementary Table S2).

\subsection{The Catalytic Center of APX is Altered in Euglenozoans}

The primary APX sequences from selected representatives, namely the plastid-bearing Arabidopsis thaliana, Glycine max, and E. gracilis, and the plastid-lacking L. major, L. seymouri, C. fasciculata, and N. esmeraldas possess the domains required for the $\mathrm{H}_{2} \mathrm{O}_{2}$-reducing APX activity (Figure 4; Supplementary Figure S1).

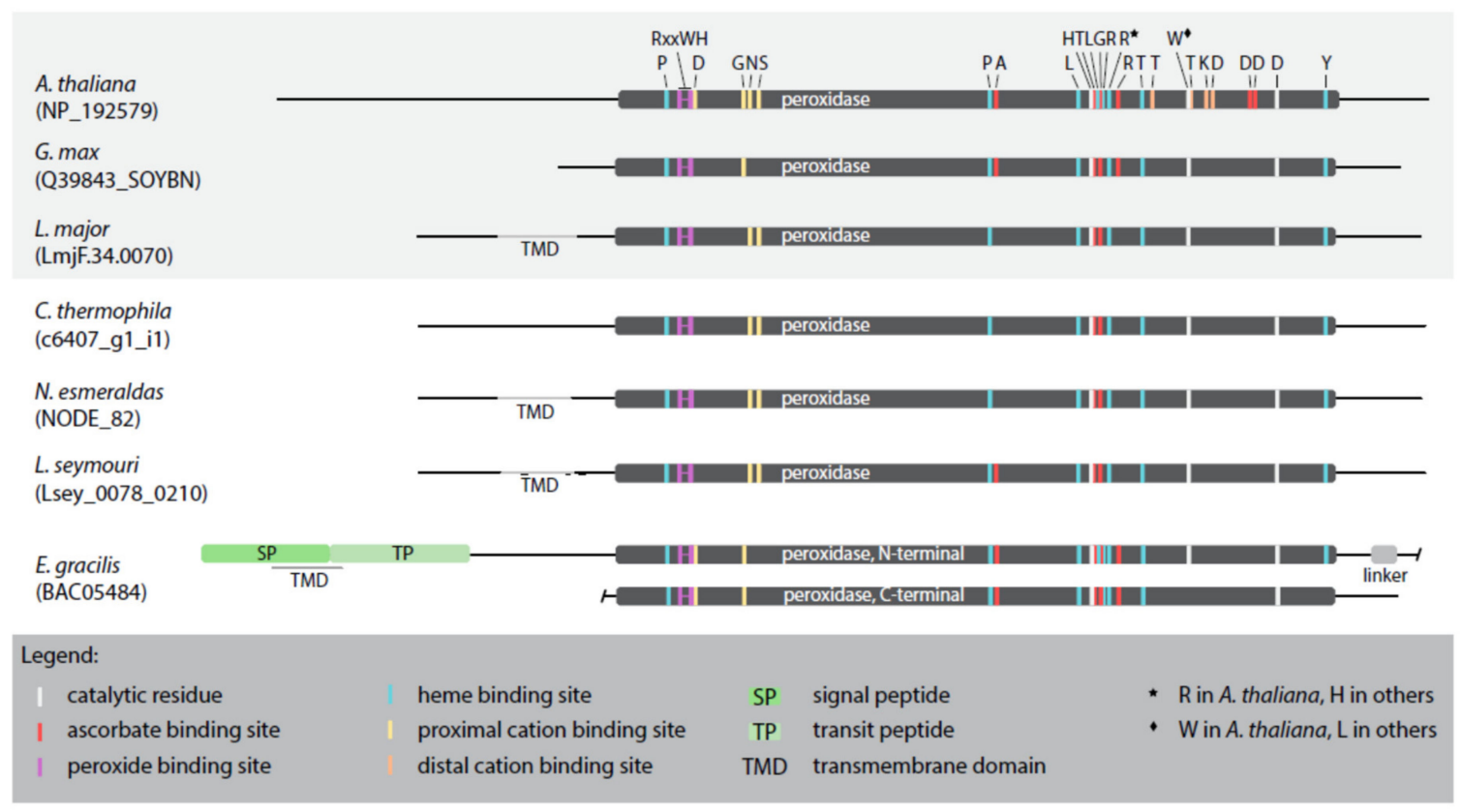

Figure 4. Schematic alignment of APX sequences from selected taxa. APXs from organisms studied previously are boxed in grey. Important amino acid residues are highlighted by different colors explained in the graphical legend.

The critical residues that coordinate binding of $\mathrm{H}_{2} \mathrm{O}_{2}$ by APX are $\mathrm{R}^{158}$, $\mathrm{W}^{161}$, and $\mathrm{H}^{162}$ (numbering according to the alignment in Supplementary Figure S1) [36], with the active site composed of the 
catalytic triad $\mathrm{H}^{293}, \mathrm{~W}^{325}$, and $\mathrm{D}^{354}$ [37]. However, in the catalytic center of the studied APX sequences $\mathrm{W}^{325}$ is invariably replaced with $\mathrm{L}^{325}$, except for the APX of $A$. thaliana (Supplementary Figure $\mathrm{S} 1$ ). Furthermore, we have identified residues critical for the heme and ascorbate binding, the number of which being species-specific (Figure 4; Supplementary Figure S1). Regarding the heme binding residues, in all analyzed sequences (except for $A$. thaliana), $\mathrm{H}^{299}$ substitutes $\mathrm{R}^{299}$, similarly to the multiple isoforms of cytosolic APX [36]. Surprisingly, when compared to the model A. thaliana APX sequence, the proximal and distal cation-binding sites have been significantly changed or lost altogether, respectively, in all inspected euglenozoans and G. max (Figure 4; Supplementary Figure S1).

\subsection{CAT Activity is Temperature-Dependent}

In consonance with the absence of the CAT-encoding gene in euglenids [25] and T. brucei [38], we did not detect any CAT activity in these species (Figure 3C; Supplementary Table S2). N. Esmeraldas exhibited the CAT activity of $10 \pm 2.4 \mathrm{U} / \mathrm{mg}$, but with the employed methodology we failed to detect any activity in Blastocrithidia sp. P57 and R. humris, despite the fact that corresponding transcripts were expressed (Figure 3C,D; Supplementary Table S2). While the rich and poor cultivation medium has a significant impact on the metabolism of $D$. papillatum, the CAT activity remained stable under different conditions (Figure 3C; Supplementary Table S2).

Recently, it has been demonstrated that the human CAT and its orthologue from a monoxenous (insect-hosts only) trypanosomatid C. fasciculata have very different temperature optima [39]. In order to investigate the thermal properties of euglenozoan CAT in more detail, we examined its activity in C. thermophila and L. seymouri, both at their optimal cultivation temperature of $23^{\circ} \mathrm{C}$, as well as at $14^{\circ} \mathrm{C}$ and $34^{\circ} \mathrm{C}$. These monoxenous species were selected because they have the highest expression and activity of CAT among the studied euglenozoans (Figure 3C,D; Supplementary Table S2), and are also thermo-tolerant, being able to withstand temperature changes $[40,41]$. In both species, the elevated temperature lowered CAT activity (Figure 3C). Nevertheless, the increased temperature caused a mild increase (1.5- and 3.7-times in C. thermophila and L. seymouri, respectively) in the mRNA level of CAT. The resulting pattern of CAT activity and transcription is rather complex. In both species, lower temperature generally resulted in increased CAT activity (Figure 3C), although the correlation between temperature and transcription levels was different for C. thermophila and L. seymouri (Figure 3D).

\subsection{Respiration Rate Does Not Correlate with CAT and APX Activities}

We assumed that organisms with high oxygen uptake require highly active systems for effective ROS detoxification. If so, CAT was the best candidate for this role, since its activity is not linked to any other system and it can provide direct and rapid reduction of $\mathrm{H}_{2} \mathrm{O}_{2}$. However, we did not find any correlation between the presence or activity of the CAT or APX detoxification systems and the rate of respiration (Figure 3E; Supplementary Table S2). Although it has the highest oxygen uptake, E. longa encodes neither CAT nor APX in its transcriptome (presumed to be highly representative [42]), and, correspondingly, their activities were lacking (Figure 3). Consistently, the dark-grown E. gracilis does not display any APX activity, with its respiration rate only slightly lower than that of E. longa (Figure 3E). Since oxygen consumption was masked by photosynthesis in the illuminated E. gracilis with fully developed plastids, we could not properly evaluate respiration in this case. The CAT activity of D. papillatum was not significantly influenced by the cultivation conditions (rich versus poor medium), even with increased respiration rate in the latter (Figure 3E). The respiration rate of thermostable C. thermophila and L. seymouri was lowest at $14{ }^{\circ} \mathrm{C}$, however the enzymatic activities were highest (Figure 3A,C,E).

\section{Discussion}

The complex phylogenetic pattern, diversity, and distribution of CAT and APX in euglenozoans testify to their importance for these protists. Indeed, E. gracilis contains a photosynthesis-specific APX shared with other phototrophic euglenophytes, along with a putative plastidial APX acquired from and 
limited to Chloroplastida (Figure 1). Moreover, both diplonemids and euglenids encode a novel clade of peroxidases with an unknown function, while most kinetoplastids share a unique hAPX-CCP enzyme exhibiting both the APX and CCP activities [43]. Surprisingly, the kinetoplastid Blastocrithidia sp. P57 and the diplonemid $R$. humris apparently lack hAPX-CCP, so the low APX activity in both species must be assigned to another, possibly horizontally transferred, yet unidentified enzyme. Another such example is CAT in D. papillatum that was gained horizontally from an alpha-proteobacterium (Figure 2C). The distribution of APX and CAT in diplonemids is best explained by a scenario, in which the predecessor of these marine protists lacked both enzymes, which were reacquired by horizontal gene transfer from either prokaryotic or eukaryotic sources (Figures 1 and 2). The importance of possessing such detoxifying systems is highlighted by the fact that this has occurred independently in several euglenozoan lineages.

For a long time, APX was considered characteristic for photosynthetic organisms, while CAT was thought to be ubiquitous in the aerobic systems [44]. However, the distribution of these enzymes in euglenozoans challenges both claims. Evidence for the presence of APX and prominent absence of CAT in Trypanosoma cruzi and Leishmania major suggest that the former contributes to the ROS scavenging also in these parasites [34]. The absence of CAT in certain parasitic trypanosomatids is likely due to an adaptation to their dixenous (two-hosts) lifestyle, as the transition in the development from the insect to the mammalian stages of T. brucei and Leishmania spp. seem to rely on $\mathrm{H}_{2} \mathrm{O}_{2}$ production $[39,45,46]$. However, the lack of CAT in dixenous kinetoplastids is not universal, as exemplified by Trypanoplasma borelli harboring a glycosomal CAT [47].

CAT and APX complement each other's function in tobacco [27], so to clarify the evolutionary context of their functional differentiation in euglenozoans, we searched for the CAT and APX sequences in genomes and/or transcriptomes of representatives, for which such data are available. From these organisms, only T. brucei, E. gracilis, and E. longa lack both the CAT genes and corresponding activity (Figure 3C,D). However, despite the presence of CAT transcripts in R. humris and Blastocrithidia sp. P57, respective enzymatic activity was below our detection limit (Figure 3C), which is not consistent with the detection of low CAT activity via heme-dependent oxygen production [29]. Our methodology is based on a spectrophotometric measurement of a decrease in $\mathrm{H}_{2} \mathrm{O}_{2}$ (for CAT) and ascorbate (for APX) levels. Although the sensitivity of oxygen detection appears to be significantly higher than that for the spectrophotometric detection of $\mathrm{H}_{2} \mathrm{O}_{2}$ reduction, we used the latter method in order to have consistent comparison for the CAT and APX enzymes. The kinetic parameters of CAT suggest yet another explanation for the lack of measurable activity in R. humris and Blastocrithidia sp. P57. The low affinity of CAT to $\mathrm{H}_{2} \mathrm{O}_{2}$ implies that it is responsible for the removal of excessive ROS when their concentration is high, while high-affinity APX modulates low concentration of ROS, necessary for cell signaling [14]. Thus, it is plausible that under the applied experimental setup R. humris and Blastocrithidia sp. P57 were not exposed to the conditions in which ROS would exceed a threshold and upregulate CAT activity.

Since at least E. longa and T. brucei have neither CAT nor APX activity, the plant-like pattern with APX complementing the lack of CAT does not apply to the euglenozoan protists. In E. gracilis, a high APX activity was limited to the phototrophic growth conditions and, supposedly, the plastid. The corresponding APX contains two homologous catalytic domains, forming an intramolecular dimeric structure and a class II plastid-targeting bipartite sequence [48]. Previously, the APX activity was demonstrated to be cytosolic [48], which is most likely an artifact of the procedure, given the presence of the encoded targeting sequence and recent proteomic evidence [49]. We propose that the high APX activity in E. gracilis, comparable with that in plant plastids [35], mainly mitigates photosynthetic ROS production in plastids, rather than amends the absence of CAT. Furthermore, the APX activity in plastid-lacking protists, assayed herein, is 3-18-times lower when compared to the phototrophic E. gracilis, suggesting that its expression in these species does not meet conditions where high amounts of ROS need to be combatted.

The catalytic properties of APX depend on the architecture of its domains, substrate binding and orienting sites. Our results show that not all previously described catalytic amino acids are conserved. 
For instance, a substitution of $\mathrm{W}$ for $\mathrm{L}$ within the catalytic triad at position 325 can apparently be tolerated and it does not affect the enzymatic activity, since G. max APX (with $\mathrm{L}^{325}$ ) shows activity comparable to the A. thaliana orthologue (with $\mathrm{W}^{325}$ ) [50,51]. Uniquely, APXs of L. major, L. seymouri, and N. esmeraldas (and, probably, other representatives of Leishmaniinae [52]) possess the N-terminal anchoring trans-membrane domain that modulates their catalytic activity. While full-length proteins exhibit specific APX activities comparable to the cytosolic counterparts, deletion of this domain from L. major caused a 5-fold decrease in activity [34]. This highlights the importance of membrane tethering for enzyme architecture or substrate accessibility for this type of APX. On the other hand, the absence of several cation-binding residues has no effect on enzymatic activity, suggesting that they may be either redundant or not critical.

ROS production is a phenomenon, accompanying aerobic life, as both photosynthesis and respiration are major sources of ROS. However, we did not document a direct link between the rate of oxygen consumption and the activity of studied peroxidases. High ROS production via respiration is considered to recruit the CAT and APX systems to limit ROS reactivity [53]. However, we posit that this correlation may not be as straightforward. An increase in oxygen uptake was documented in D. papillatum, cultivated in the nutrient-poor medium, yet this had no effect on its CAT activity. Surprisingly, in thermostable $C$. thermophila and L. seymouri, elevated temperature triggered an increase in respiration, but a decrease in the activities of both CAT and APX. That transcript abundance did not follow the same pattern as activity can be explained by the key role of post-transcriptional regulation in the gene expression of euglenids and trypanosomatids [54-58]. Indeed, weak-to-moderate correlation has been observed between transcript abundance and protein levels in both trypanosomatids and Euglena. This suggests an important role of mRNA turnover, translational efficiency and protein degradation in modulating biological responses in these protists [57]. All euglenozoan protists are known for polycistronic transcription and the important role of post-transcriptional processes. Hence, the rather weak correlation between transcript levels and enzymatic activities of CAT and APX is not unexpected.

To conclude, despite the fact that the ROS detoxification systems in plants are upregulated under different conditions, we documented a similar activity pattern only for CAT in thermostable kinetoplastids, but not in the other studied euglenozoans. When present, these peroxidases appear to be constitutively transcribed, yet the extent of their enzymatic activity varies widely across the examined species. CAT and APX are retained (or horizontally acquired) only in a subset of studied protists, which is reflected in their complex phylogenies.

\section{Materials and Methods}

\subsection{Sequence Searches and Phylogenetic Analyses}

CAT sequences from D. papillatum were found by tBLASTn [59] search in an unpublished genome and transcriptome assembly using kinetoplastid sequences, identified previously [29], as queries. The D. papillatum sequences served as queries for searches in the transcriptomes of other diplonemid species - Diplonema japonicum, Rhynchopus humris, Lacrimia lanifica, Sulcionema specki, Artemidia motanka, and Namystynia karyoxenos.

APX sequences were downloaded from RedOxiBase [60] and GenBank [61] databases. These served as queries and references for APX identification in all studied euglenozoans and other protists. To distinguish between APX and cytochrome $c$ peroxidases, with which they share the common phylogenetic origin [43], all euglenozoan sequences were submitted to the InterProScan [62]. Only those with identified APX domains or strong affiliation to the reference APX clades were retained for further phylogenetic analysis.

Sequences were clustered (50\% identity and 80\% coverage) using MMseqs2 [63]. Datasets were aligned by MAFFT [64] and poorly aligned positions were discarded by trimAl [65] using -gt 0.5 option. Maximum likelihood trees were inferred from the alignments using the LG + C20 + F + G model and 
the posterior mean site frequency method [66], LG + F + G guide tree in the IQ-TREE software [67] and employing the strategy of rapid bootstrapping followed by a "thorough" maximum likelihood search with 1000 bootstrap replicates.

\subsection{Localization Predictions}

To assess a putative subcellular localization of all studied euglenozoan proteins, PrediSi [68], NommPred (in kinetoplastid setting; [69]), TargetP v.2.0 [70], and MultiLoc2 (in fungal and animal settings; [71]) tools were employed. Glycosomal predictions were determined by an in-house python script based on previously identified targeting signals in kinetoplastids [28]. The number of transmembrane domains was predicted by TMHMM [72] or Phobius [73], implemented in the Geneious Prime software [74].

\subsection{Transcript Expression Levels}

Trimmed RNA-Seq reads were mapped onto the assembled transcriptomes using BBMap (part of the BBTools suite; https://jgi.doe.gov/data-and-tools/bbtools/). The expression values for each transcript were calculated as Fragments Per Kilobase of transcript per Million mapped reads (FPKM). From these, TPM (Transcripts Per Million) values were calculated as FPKM $/ \operatorname{sum}(\mathrm{FPKMs}) \times 10^{6}$. For proteins with several transcript models, mean TPM was calculated.

\subsection{Strains and Culture Conditions}

D. papillatum cells were inoculated into the nutrient-rich and nutrient-poor media, to a final concentration $5 \times 10^{5}$ cells $/ \mathrm{mL}$. The nutrient-rich medium contained $36 \mathrm{~g} / \mathrm{L}$ sea salts (Red Sea), and $1 \%(\mathrm{v} / \mathrm{v})$ horse serum (Sigma-Aldrich, St. Louise, USA), and $1 \mathrm{~g} / \mathrm{L}$ tryptone (Duchefa Biochemie, Amsterdam, Netherlands), while the nutrient-poor medium consisted of $36 \mathrm{~g} / \mathrm{L}$ sea salts, $1 \%$ (v/v) horse serum, and $0.01 \mathrm{~g} / \mathrm{L}$ tryptone [75].

R. humris was cultivated in artificial sea water containing 3.6\% sea salts (Sigma-Aldrich), enriched with $1 \%(\mathrm{v} / \mathrm{v})$ heat-inactivated horse serum (Sigma-Aldrich), and $0.025 \mathrm{~g} / \mathrm{L} \mathrm{LB}$ broth powder (Amresco, Solon, USA) [76].

Blastocrithidia sp. P57 was cultivated in a medium composed of $40 \%(\mathrm{v} / \mathrm{v})$ Schneider medium, $40 \%(\mathrm{v} / \mathrm{v})$ RPMI medium, and 20\% (v/v) inactivated fetal bovine serum (all Sigma-Aldrich).

L. seymouri and C. thermophila were cultivated at $23{ }^{\circ} \mathrm{C}$ in the Brain Heart Infusion medium (Sigma-Aldrich) supplemented with $10 \mu \mathrm{g} / \mathrm{mL}$ of hemin (Jena Bioscience, Jena, Germany), $10 \%$ fetal bovine serum, 100 units/mL of penicillin, and $100 \mu \mathrm{g} / \mathrm{mL}$ of streptomycin (all Sigma-Aldrich) [77]. For experiments at different temperatures $\left(14{ }^{\circ} \mathrm{C}\right.$ and $\left.34{ }^{\circ} \mathrm{C}\right)$, cells were seeded at a concentration of $3 \times 10^{5}$ cells $/ \mathrm{mL}$ and cultured for $72 \mathrm{~h}$ as described previously [40].

T. brucei (strain 29-13) was cultured at $27^{\circ} \mathrm{C}$ in SDM79 medium (GE Healthcare, Chicago, USA) containing $10 \%(\mathrm{v} / \mathrm{v})$ heat-inactivated fetal bovine serum (Biosera, Nuaillé, France) and $2.5 \mathrm{mg} / \mathrm{mL}$ hemin [78].

E. gracilis cells were cultivated statically at $27^{\circ} \mathrm{C}$ under constant illumination $\left(10 \mu \mathrm{m} / \mathrm{m}^{2} \mathrm{~s}^{1}\right)$ and dark in liquid Hutner medium [79]. E. longa cells were cultivated statically under constant illumination $\left(10 \mu \mathrm{m} / \mathrm{m}^{2} \mathrm{~s}^{1}\right)$ at $27^{\circ} \mathrm{C}$ in Cramer-Myers medium supplemented with ethanol $(0.8 \% \mathrm{v} / \mathrm{v})$ [80].

\subsection{RNA Isolation, Sequencing and Read Processing}

Total RNA of $5 \times 10^{7}$ cells from each L. seymouri and C. thermophila shifted to $14^{\circ} \mathrm{C}$ was isolated using the RNeasy Mini kit (Qiagen, Hilden, Germany) according to the manufacturer's instruction for three independent biological replicates. Paired-end strand-specific cDNA libraries were sequenced on Illumina NovaSeq platform (Macrogen Inc., Seoul, Korea). RNA-Seq reads were adapter and quality trimmed using BBDuk (part of the BBTools suite). As described above, trimmed reads were mapped onto previously assembled transcriptomes $[40,41]$. The raw sequencing data for $L$. seymouri 
and C. thermophila are available at NCBI (https://www.ncbi.nlm.nih.gov/) as BioProjects PRJNA611003 and PRJNA611063, respectively.

\subsection{Protein Isolation}

Five million cells of D. papillatum and R. humris were incubated with $2 \mathrm{mg}$ of digitonin (AppliChem, Darmstadt, Germany) at room temperature for $5 \mathrm{~min}$. Aliquot of $10^{6}$ lysed cells were used for activity measurements. $5 \times 10^{8}$ T. brucei, L. seymouri, C. thermophila, N. esmeraldas, and Blastocrithidia sp. P57 cells were lysed on ice with $2 \%(\mathrm{w} / \mathrm{v})$ dodecyl maltoside in $0.5 \mathrm{M}$ aminocaproic acid (both AppliChem) for $1 \mathrm{~h}$ with subsequent 30 min centrifugation at $21,300 \times g$ at $4{ }^{\circ} \mathrm{C} .10^{5}$ E. gracilis and E. longa cells were disrupted using $200 \mathrm{mg}$ of $1 \mathrm{~mm}$ silica spheres (Silica matrix C; MP Biomedicals, Irvine, USA), and cycle of $3 \times 15 \mathrm{~s}, 4.0 \mathrm{M} / \mathrm{S}$ on FastPrep-24 (MP Biomedicals) with cooling on ice between cycles. Residual intact cells were separated from lysate by centrifugation at $1800 \times g$ for $10 \min$ at $4{ }^{\circ} \mathrm{C}$. Supernatant was used for activity measurements.

Protein concentration in cell lysates was determined using Bradford assay [81].

\subsection{Measurements of Activities}

Both CAT and APX activity were measured at $25{ }^{\circ} \mathrm{C}$ in whole-cell lysates. CAT activity was measured in total volume $1.3 \mathrm{~mL}$ that comprised $50 \mathrm{mM} \mathrm{KPi} \mathrm{pH} \mathrm{7.2,} \mathrm{0.005 \%} \mathrm{(v/v)} \mathrm{H}_{2} \mathrm{O}_{2}$, and $10 \mu \mathrm{L}$ of kinetoplastid lysate (T. brucei, L. seymouri, C. thermophila, N. esmeraldas, or Blastocrithidia sp. P57) or $100 \mu \mathrm{L}$ of diplonemid lysate (D. papillatum or R. humris) or euglenid lysate (E. gracilis or E. longa). Activity of CAT was monitored for 2-4 min as a decrease in absorbance at $240 \mathrm{~nm}$ in the cuvette for UV-VIS spectra (Varian-Agilent Quartz Semi-Micro Cuvette Cell, Agilent, Santa Clara, USA). Activity $\mathrm{U}$ was calculated as the amount of enzyme that reduces $1 \mu \mathrm{mol}$ of $\mathrm{H}_{2} \mathrm{O}_{2}\left(\varepsilon_{240}=43.6 \mathrm{M}^{-1} \mathrm{~cm}^{-1}\right)$ per $1 \mathrm{~min}$. Specific activity was calculated as $\mathrm{U}$ per mg of cell proteins.

APX activity was measured analogously to CAT activity with the addition of freshly prepared $15 \mu \mathrm{M}$ ascorbate (AppliChem). The activity was monitored for $2-4 \mathrm{~min}$ at $274 \mathrm{~nm}$ as a decrease in absorbance in the cuvette for UV-VIS spectra (Agilent). Activity U was calculated as the amount of enzyme required for a reduction of $1 \mu \mathrm{mol}$ of ascorbic acid $\left(\varepsilon_{274}=14,900 \mathrm{M}^{-1} \mathrm{~cm}^{-1}\right)$ per $1 \mathrm{~min}$. Specific activity was calculated as $\mathrm{U}$ per $\mathrm{mg}$ of cell proteins.

In order to distinguish between $\mathrm{H}_{2} \mathrm{O}_{2}$ and ascorbate absorption spectra, we scanned absorbance of each substrate from 200 to $350 \mathrm{~nm}$. Both molecules had absorption peaks at $300 \mathrm{~nm}$, the wavelength at which CAT and APX activities are routinely detected [10,35]. After reducing the concentration of both substrates compared to the original protocols, $0.005 \%(\mathrm{v} / \mathrm{v}) \mathrm{H}_{2} \mathrm{O}_{2}$ displayed an additional peak at $240 \mathrm{~nm}$. Thus, we picked this wavelength $(240 \mathrm{~nm})$ for CAT measurements, because ascorbate did not absorb in this area. The control for CAT activity was the formation of oxygen that was visible in the cuvette in the form of bubbles. Since ascorbate displayed only one absorption peak around $300 \mathrm{~nm}$, we adjusted the wavelength to $274 \mathrm{~nm}$ where $0.005 \%(\mathrm{v} / \mathrm{v}) \mathrm{H}_{2} \mathrm{O}_{2}$ was not detected and only an increase in reduced ascorbate was monitored. Our optimized assay for APX activity measurement was closest to the protocol published previously [82], in which the concentration of ascorbate varied from 10 to $80 \mu \mathrm{M}$ and oxidation of substrate was monitored at $265 \mathrm{~nm}$ with extinction coefficient for ascorbate $\varepsilon_{274}=14,900 \mathrm{M}^{-1} \mathrm{~cm}^{-1}$.

Each experiment was performed in two biological replicates. Each biological replicate consisted of 2-6 technical replicates. Statistical significance of differences between organisms was evaluated by unpaired $t$-test.

\subsection{Oxygen Uptake Analysis}

Clark oxygen electrode (Oxytherm System; Hansatech Instruments, Norfolk, UK) was used for measuring the oxygen consumption by intact cells. Each culture in the logarithmic growth phase was diluted to a concentration of $10^{6}$ cells $/ \mathrm{mL}$. The electrode chamber was filled with $1 \mathrm{~mL}$ of culture 
and oxygen consumption was recorded for 4-6 min. Final values were calculated as the difference in oxygen consumption per 1 min caused by $10^{6}$ cells.

Each experiment was performed in two biological replicates. Each biological replicate consisted of two to six technical replicates. Statistical significance of differences between organisms was evaluated by unpaired $t$-test.

Supplementary Materials: The following are available online at http://www.mdpi.com/2076-0817/9/4/317/s1, Figure S1: Full alignment of APX sequences from selected species. APX domains, signal and transit peptide, and linker are boxed by a colored background corresponding to domain colors in Figure 4. Important amino acid residues are highlighted in different colors corresponding to colors in Figure 4. Transmembrane domains are underlined. Table S1: Predicted subcellular localization of euglenozoan sequences used in this study. Table S2: Inferred expression levels and measurements of enzyme activities and oxygen uptake in studied euglenozoans. File S1: Maximum-likelihood phylogenetic tree of Euglenozoa HPX possessing APX domains in Newick format. File S2: Maximum-likelihood phylogenetic tree of Euglenozoa CAT in Newick format.

Author Contributions: Conceptualization, I.Š.-S. and K.Z.; methodology, I.Š.-S.; software, K.Z. and Z.F.; validation, I.Š.-S., K.Z., and Z.F.; formal analysis, I.Š.-S., K.Z., and B.B.; investigation, I.Š.-S. and K.Z.; resources, I.Š.-S. and V.Y.; data curation, I.Š.-S., K.Z., B.B. and Z.F.; writing—original draft preparation, I.Š.-S., K.Z., and Z.F.; writing—review and editing, I.Š.-S., K.Z., Z.F., V.Y., and J.L.; visualization, I.Š.-S., K.Z. and Z.F.; supervision, V.Y. and J.L.; project administration, I.S..-S. and K.Z.; funding acquisition, I.Š.-S., V.Y. and J.L. All authors have read and agreed to the published version of the manuscript.

Funding: This research was funded by Czech Ministry of Education (project LM2015042), CERIT-Scientific Cloud (project LM2015085), ERC CZ (project LL1601), the Grant Agency of Czech Republic (projects 18-15962S and 20-07186S), the European Regional Funds (project OPVVV/0000759), the Grant Agency of the Slovak Ministry of Education and the Academy of Sciences (projects 1/0781/19 and 1/0387/17), and the Slovak Research and Development Agency (project APVV-0286-12).

Acknowledgments: We thank members of our laboratories for stimulating discussions.

Conflicts of Interest: V.Y. is an Academic Editor of Pathogens. Other authors declare no conflict of interest. The funders had no role in the design of the study; in the collection, analyses, or interpretation of data; in the writing of the manuscript, or in the decision to publish the results.

\section{References}

1. Bilinski, T. Oxygen toxicity and microbial evolution. Biosystems 1991, 24, 305-312. [CrossRef]

2. Lü, J.M.; Lin, P.H.; Yao, Q.; Chen, C. Chemical and molecular mechanisms of antioxidants: Experimental approaches and model systems. J. Cell Mol. Med. 2010, 14, 840-860. [CrossRef] [PubMed]

3. Gill, S.S.; Tuteja, N. Reactive oxygen species and antioxidant machinery in abiotic stress tolerance in crop plants. Plant Physiol. Biochem. 2010, 48, 909-930. [CrossRef]

4. Avery, S.V. Molecular targets of oxidative stress. Biochem. J. 2011, 434, 201-210. [CrossRef] [PubMed]

5. Apel, K.; Hirt, H. Reactive oxygen species: Metabolism, oxidative stress, and signal transduction. Annu. Rev. Plant Biol. 2004, 55, 373-399. [CrossRef]

6. Asada, K.; Takahashi, M. Production and Scavenging of Active Oxygen in Chloroplasts; Photoinhibition, D.J., Kyle, C.B., Arntzen, C.J., Eds.; Elsevier: Amsterdam, The Netherlands, 1987; pp. 227-287.

7. Bowler, C.; Montagu, M.V.; Inze, D. Superoxide dismutase and stress tolerance. Annu. Rev. Plant Physiol. Plant Mol. Biol. 1992, 43, 83-116. [CrossRef]

8. Willekens, H.; Chamnongpol, S.; Davey, M.; Schraudner, M.; Langebartels, C.; Van Montagu, M.; Inze, D.; Van Camp, W. Catalase is a sink for $\mathrm{H}_{2} \mathrm{O}_{2}$ and is indispensable for stress defence in $\mathrm{C} 3$ plants. EMBO J. 1997, 16, 4806-4816. [CrossRef]

9. Takeda, T.; Yoshimura, K.; Yoshii, M.; Kanahoshi, H.; Miyasaka, H.; Shigeoka, S. Molecular characterization and physiological role of ascorbate peroxidase from halotolerant Chlamydomonas sp. W80 strain. Arch. Biochem. Biophys. 2000, 376, 82-90. [CrossRef]

10. Wilkinson, S.R.; Obado, S.O.; Mauricio, I.L.; Kelly, J.M. Trypanosoma cruzi expresses a plant-like ascorbate-dependent hemoperoxidase localized to the endoplasmic reticulum. Proc. Natl. Acad. Sci. USA 2002, 99, 13453-13458. [CrossRef]

11. Shigeoka, S.; Nakano, Y.; Kitaoka, S. Metabolism of hydrogen peroxide in Euglena gracilis Z by L-ascorbic acid peroxidase. Biochem. J. 1980, 186, 377-380. [CrossRef] 
12. Caverzan, A.; Passaia, G.; Rosa, S.B.; Ribeiro, C.W.; Lazzarotto, F.; Margis-Pinheiro, M. Plant responses to stresses: Role of ascorbate peroxidase in the antioxidant protection. Genet. Mol. Biol. 2012, 35 (Suppl. 4), 1011-1019. [CrossRef] [PubMed]

13. Vlasits, J.; Jakopitsch, C.; Schwanninger, M.; Holubar, P.; Obinger, C. Hydrogen peroxide oxidation by catalase-peroxidase follows a non-scrambling mechanism. FEBS Lett. 2007, 581, 320-324. [CrossRef] [PubMed]

14. Mittler, R. Oxidative stress, antioxidants and stress tolerance. Trends Plant Sci. 2002, 7, 405-410. [CrossRef]

15. De Marco, A.; Roubelakis-Angelakis, K.A. The complexity of enzymic control of hydrogen peroxide concentration may affect the regeneration potential of plant protoplasts. Plant Physiol. 1996, 110, 137-145. [CrossRef]

16. Shigeoka, S.; Ishikawa, T.; Tamoi, M.; Miyagawa, Y.; Takeda, T.; Yabuta, Y.; Yoshimura, K. Regulation and function of ascorbate peroxidase isoenzymes. J. Exp. Bot. 2002, 53, 1305-1319. [CrossRef]

17. Teixeira, F.K.; Menezes-Benavente, L.; Margis, R.; Margis-Pinheiro, M. Analysis of the molecular evolutionary history of the ascorbate peroxidase gene family: Inferences from the rice genome. J. Mol. Evol. 2004, 59, 761-770. [CrossRef]

18. Teixeira, F.K.; Menezes-Benavente, L.; Galvao, V.C.; Margis, R.; Margis-Pinheiro, M. Rice ascorbate peroxidase gene family encodes functionally diverse isoforms localized in different subcellular compartments. Planta 2006, 224, 300-314. [CrossRef]

19. Mittler, R.; Vanderauwera, S.; Gollery, M.; Van Breusegem, F. Reactive oxygen gene network of plants. Trends Plant Sci. 2004, 9, 490-498. [CrossRef]

20. Glorieux, C.; Calderon, P.B. Catalase, a remarkable enzyme: Targeting the oldest antioxidant enzyme to find a new cancer treatment approach. Biol. Chem. 2017, 398, 1095-1108. [CrossRef]

21. Fairlamb, A.H.; Blackburn, P.; Ulrich, P.; Chait, B.T.; Cerami, A. Trypanothione: A novel bis(glutathionyl)spermidine cofactor for glutathione reductase in trypanosomatids. Science 1985, 227, 1485-1487. [CrossRef]

22. Carnieri, E.G.; Moreno, S.N.; Docampo, R. Trypanothione-dependent peroxide metabolism in Trypanosoma cruzi different stages. Mol. Biochem. Parasitol. 1993, 61,79-86. [CrossRef]

23. Adak, S.; Pal, S. Ascorbate peroxidase acts as a novel determiner of redox homeostasis in Leishmania. Antioxid. Redox Signal. 2013, 19, 746-754. [CrossRef] [PubMed]

24. Montrichard, F.; Le Guen, F.; Laval-Martin, D.L.; Davioud-Charvet, E. Evidence for the co-existence of glutathione reductase and trypanothione reductase in the non-trypanosomatid Euglenozoa: Euglena gracilis Z. FEBS Lett. 1999, 442, 29-33. [CrossRef]

25. Zimorski, V.; Rauch, C.; van Hellemond, J.J.; Tielens, A.G.M.; Martin, W.F. The mitochondrion of Euglena gracilis. Adv. Exp. Med. Biol. 2017, 979, 19-37.

26. Butenko, A.; Opperdoes, F.R.; Flegontova, O.; Horak, A.; Hampl, V.; Keeling, P.; Gawryluk, R.M.R.; Tikhonenkov, D.; Flegontov, P.; Lukeš, J. Evolution of metabolic capabilities and molecular features of diplonemids, kinetoplastids, and euglenids. BMC Biol. 2020, 18, 23. [CrossRef]

27. Mittler, R.; Herr, E.H.; Orvar, B.L.; van Camp, W.; Willekens, H.; Inze, D.; Ellis, B.E. Transgenic tobacco plants with reduced capability to detoxify reactive oxygen intermediates are hyperresponsive to pathogen infection. Proc. Natl. Acad. Sci. USA 1999, 96, 14165-14170. [CrossRef]

28. Opperdoes, F.R.; Szikora, J.P. In silico prediction of the glycosomal enzymes of Leishmania major and trypanosomes. Mol. Biochem. Parasitol. 2006, 147, 193-206. [CrossRef]

29. Bianchi, C.; Kostygov, A.Y.; Kraeva, N.; Záhonová, K.; Horáková, E.; Sobotka, R.; Lukeš, J.; Yurchenko, V. An enigmatic catalase of Blastocrithidia. Mol. Biochem. Parasitol. 2019, 232, 111199. [CrossRef]

30. Kraeva, N.; Horáková, E.; Kostygov, A.; Kořený, L.; Butenko, A.; Yurchenko, V.; Lukeš, J. Catalase in Leishmaniinae: With me or against me? Infect. Genet. Evol. 2017, 50, 121-127. [CrossRef]

31. Schott, E.J.; Di Lella, S.; Bachvaroff, T.R.; Amzel, L.M.; Vasta, G.R. Lacking catalase, a protistan parasite draws on its photosynthetic ancestry to complete an antioxidant repertoire with ascorbate peroxidase. BMC Evol. Biol. 2019, 19, 146. [CrossRef]

32. Adl, S.M.; Bass, D.; Lane, C.E.; Lukeš, J.; Schoch, C.L.; Smirnov, A.; Agatha, S.; Berney, C.; Brown, M.W.; Burki, F.; et al. Revisions to the classification, nomenclature, and diversity of eukaryotes. J. Eukaryot. Microbiol. 2019, 66, 4-119. [CrossRef] [PubMed] 
33. Lukeš, J.; Skalický, T.; Týč, J.; Votýpka, J.; Yurchenko, V. Evolution of parasitism in kinetoplastid flagellates. Mol. Biochem. Parasitol. 2014, 195, 115-122. [CrossRef] [PubMed]

34. Adak, S.; Datta, A.K. Leishmania major encodes an unusual peroxidase that is a close homologue of plant ascorbate peroxidase: A novel role of the transmembrane domain. Biochem. J. 2005, 390, 465-474. [CrossRef] [PubMed]

35. Mittler, R.; Zilinskas, B.A. Purification and characterization of pea cytosolic ascorbate peroxidase. Plant Physiol. 1991, 97, 962-968. [CrossRef] [PubMed]

36. Wada, K.; Tada, T.; Nakamura, Y.; Ishikawa, T.; Yabuta, Y.; Yoshimura, K.; Shigeoka, S.; Nishimura, K. Crystal structure of chloroplastic ascorbate peroxidase from tobacco plants and structural insights into its instability. J. Biochem. 2003, 134, 239-244. [CrossRef] [PubMed]

37. Pitsch, N.T.; Witsch, B.; Baier, M. Comparison of the chloroplast peroxidase system in the chlorophyte Chlamydomonas reinhardtii, the bryophyte Physcomitrella patens, the lycophyte Selaginella moellendorffii and the seed plant Arabidopsis thaliana. BMC Plant Biol. 2010, 10, 133. [CrossRef] [PubMed]

38. Opperdoes, F.R.; Butenko, A.; Flegontov, P.; Yurchenko, V.; Lukeš, J. Comparative metabolism of free-living Bodo saltans and parasitic trypanosomatids. J. Eukaryot. Microbiol. 2016, 63, 657-678. [CrossRef]

39. Horáková, E.; Faktorová, D.; Kraeva, N.; Kaur, B.; Van Den Abbeele, J.; Yurchenko, V.; Lukeš, J. Catalase compromises the development of the insect and mammalian stages of Trypanosoma brucei. FEBS J. 2020, 287, 964-977. [CrossRef]

40. Ishemgulova, A.; Butenko, A.; Kortišová, L.; Boucinha, C.; Grybchuk-Ieremenko, A.; Morelli, K.A.; Tesařová, M.; Kraeva, N.; Grybchuk, D.; Pánek, T.; et al. Molecular mechanisms of thermal resistance of the insect trypanosomatid Crithidia thermophila. PLoS ONE 2017, 12, e0174165. [CrossRef]

41. Kraeva, N.; Butenko, A.; Hlaváčová, J.; Kostygov, A.; Myškova, J.; Grybchuk, D.; Leštinová, T.; Votýpka, J.; Volf, P.; Opperdoes, F.; et al. Leptomonas seymouri: Adaptations to the dixenous life cycle analyzed by genome sequencing, transcriptome profiling and co-infection with Leishmania donovani. PLoS Pathog. 2015, 11, e1005127. [CrossRef]

42. Záhonová, K.; Füssy, Z.; Birčák, E.; Novák-Vanclová, A.M.G.; Klimeš, V.; Vesteg, M.; Krajčovič, J.; Oborník, M.; Eliáš, M. Peculiar features of the plastids of the colourless alga Euglena longa and photosynthetic euglenophytes unveiled by transcriptome analyses. Sci. Rep. 2018, 8, 17012. [CrossRef] [PubMed]

43. Zámocký, M.; Gasselhuber, B.; Furtmüller, P.G.; Obinger, C. Turning points in the evolution of peroxidase-catalase superfamily: Molecular phylogeny of hybrid heme peroxidases. Cell Mol. Life Sci. 2014, 71, 4681-4696. [CrossRef] [PubMed]

44. Asada, K. Ascorbate peroxidase-A hydrogen peroxide-scavenging enzyme in plants. Physiol. Plant 1992, 85, 235-241. [CrossRef]

45. Mittra, B.; Cortez, M.; Haydock, A.; Ramasamy, G.; Myler, P.J.; Andrews, N.W. Iron uptake controls the generation of Leishmania infective forms through regulation of ROS levels. J. Exp. Med. 2013, 210, 401-416. [CrossRef]

46. Khan, Y.A.; Andrews, N.W.; Mittra, B. ROS regulate differentiation of visceralizing Leishmania species into the virulent amastigote form. Parasitol. Open 2018, 4, e19. [CrossRef]

47. Opperdoes, F.R.; Nohýnková, E.; Van Schaftingen, E.; Lambeir, A.M.; Veenhuis, M.; Van Roy, J. Demonstration of glycosomes (microbodies) in the Bodonid flagellate Trypanoplasma borelli (Protozoa, Kinetoplastida). Mol. Biochem. Parasitol. 1988, 30, 155-163. [CrossRef]

48. Ishikawa, T.; Tajima, N.; Nishikawa, H.; Gao, Y.; Rapolu, M.; Shibata, H.; Sawa, Y.; Shigeoka, S. Euglena gracilis ascorbate peroxidase forms an intramolecular dimeric structure: Its unique molecular characterization. Biochem. J. 2010, 426, 125-134. [CrossRef]

49. Novák Vanclová, A.M.G.; Zoltner, M.; Kelly, S.; Soukal, P.; Záhonová, K.; Füssy, Z.; Ebenezer, T.E.; Lacová Dobáková, E.; Eliáš, M.; Lukeš, J.; et al. Metabolic quirks and the colourful history of the Euglena gracilis secondary plastid. New Phytol. 2020, 225, 1578-1592. [CrossRef]

50. Lazzarotto, F.; Teixeira, F.K.; Rosa, S.B.; Dunand, C.; Fernandes, C.L.; Fontenele Ade, V.; Silveira, J.A.; Verli, H.; Margis, R.; Margis-Pinheiro, M. Ascorbate peroxidase-related (APx-R) is a new heme-containing protein functionally associated with ascorbate peroxidase but evolutionarily divergent. New Phytol. 2011, 191, 234-250. [CrossRef] 
51. Koussevitzky, S.; Suzuki, N.; Huntington, S.; Armijo, L.; Sha, W.; Cortes, D.; Shulaev, V.; Mittler, R. Ascorbate peroxidase 1 plays a key role in the response of Arabidopsis thaliana to stress combination. J. Biol. Chem. 2008, 283, 34197-34203. [CrossRef]

52. Kostygov, A.Y.; Yurchenko, V. Revised classification of the subfamily Leishmaniinae (Trypanosomatidae). Folia Parasitol. 2017, 64, 020. [CrossRef] [PubMed]

53. Ajithkumar, I.P.; Panneerselvam, R. ROS scavenging system, osmotic maintenance, pigment and growth status of Panicum sumatrense roth under drought stress. Cell Biochem. Biophys. 2014, 68, 587-595. [CrossRef]

54. Maslov, D.A.; Opperdoes, F.R.; Kostygov, A.Y.; Hashimi, H.; Lukeš, J.; Yurchenko, V. Recent advances in trypanosomatid research: genome organization, expression, metabolism, taxonomy and evolution. Parasitology 2019, 146, 1-27. [CrossRef] [PubMed]

55. Záhonová, K.; Füssy, Z.; Oborník, M.; Eliáš, M.; Yurchenko, V. RuBisCO in non-photosynthetic alga Euglena longa: Divergent features, transcriptomic analysis and regulation of complex formation. PLoS ONE 2016, 11, e0158790.

56. Ebenezer, T.E.; Zoltner, M.; Burrell, A.; Nenarokova, A.; Novák Vanclová, A.M.G.; Prasad, B.; Soukal, P.; Santana-Molina, C.; O'Neill, E.; Nankissoor, N.N.; et al. Transcriptome, proteome and draft genome of Euglena gracilis. BMC Biol. 2019, 17, 11. [CrossRef]

57. Smircich, P.; Eastman, G.; Bispo, S.; Duhagon, M.A.; Guerra-Slompo, E.P.; Garat, B.; Goldenberg, S.; Munroe, D.J.; Dallagiovanna, B.; Holetz, F.; et al. Ribosome profiling reveals translation control as a key mechanism generating differential gene expression in Trypanosoma cruzi. BMC Genom. 2015, 16, 443. [CrossRef]

58. Parsons, M.; Myler, P.J. Illuminating parasite protein production by ribosome profiling. Trends Parasitol. 2016, 32, 446-457. [CrossRef]

59. Altschul, S.F.; Madden, T.L.; Schaffer, A.A.; Zhang, J.; Zhang, Z.; Miller, W.; Lipman, D.J. Gapped BLAST and PSI-BLAST: A new generation of protein database search programs. Nucleic Acids Res. 1997, 25, 3389-3402. [CrossRef]

60. Savelli, B.; Li, Q.; Webber, M.; Jemmat, A.M.; Robitaille, A.; Zamocky, M.; Mathe, C.; Dunand, C. RedoxiBase: A database for ROS homeostasis regulated proteins. Redox Biol. 2019, 26, 101247. [CrossRef]

61. Benson, D.A.; Cavanaugh, M.; Clark, K.; Karsch-Mizrachi, I.; Ostell, J.; Pruitt, K.D.; Sayers, E.W. GenBank. Nucleic Acids Res. 2018, 46, D41-D47. [CrossRef]

62. Jones, P.; Binns, D.; Chang, H.Y.; Fraser, M.; Li, W.; McAnulla, C.; McWilliam, H.; Maslen, J.; Mitchell, A.; Nuka, G.; et al. InterProScan 5: Genome-scale protein function classification. Bioinformatics 2014, 30, 1236-1240. [CrossRef] [PubMed]

63. Steinegger, M.; Soding, J. MMseqs2 enables sensitive protein sequence searching for the analysis of massive data sets. Nat. Biotechnol. 2017, 35, 1026-1028. [CrossRef] [PubMed]

64. Katoh, K.; Standley, D.M. MAFFT multiple sequence alignment software version 7: Improvements in performance and usability. Mol. Biol. Evol. 2013, 30, 772-780. [CrossRef] [PubMed]

65. Capella-Gutiérrez, S.; Silla-Martinez, J.M.; Gabaldon, T. trimAl: A tool for automated alignment trimming in large-scale phylogenetic analyses. Bioinformatics 2009, 25, 1972-1973. [CrossRef]

66. Wang, H.C.; Minh, B.Q.; Susko, E.; Roger, A.J. Modeling site heterogeneity with posterior mean site frequency profiles accelerates accurate phylogenomic estimation. Syst. Biol. 2018, 67, 216-235. [CrossRef]

67. Nguyen, L.T.; Schmidt, H.A.; von Haeseler, A.; Minh, B.Q. IQ-TREE: A fast and effective stochastic algorithm for estimating maximum-likelihood phylogenies. Mol. Biol. Evol. 2015, 32, 268-274. [CrossRef]

68. Hiller, K.; Grote, A.; Scheer, M.; Munch, R.; Jahn, D. PrediSi: Prediction of signal peptides and their cleavage positions. Nucleic Acids Res. 2004, 32, W375-W379. [CrossRef]

69. Kume, K.; Amagasa, T.; Hashimoto, T.; Kitagawa, H. NommPred: Prediction of mitochondrial and mitochondrion-related organelle proteins of nonmodel organisms. Evol. Bioinform. Online 2018, 14, 1176934318819835. [CrossRef]

70. Almagro Armenteros, J.J.; Salvatore, M.; Emanuelsson, O.; Winther, O.; von Heijne, G.; Elofsson, A.; Nielsen, H. Detecting sequence signals in targeting peptides using deep learning. Life Sci. Alliance 2019, 2, e201900429. [CrossRef]

71. Blum, T.; Briesemeister, S.; Kohlbacher, O. MultiLoc2: Integrating phylogeny and Gene Ontology terms improves subcellular protein localization prediction. BMC Bioinform. 2009, 10, 274. [CrossRef] 
72. Krogh, A.; Larsson, B.; von Heijne, G.; Sonnhammer, E.L. Predicting transmembrane protein topology with a hidden Markov model: Application to complete genomes. J. Mol. Biol. 2001, 305, 567-580. [CrossRef] [PubMed]

73. Käll, L.; Krogh, A.; Sonnhammer, E.L. Advantages of combined transmembrane topology and signal peptide prediction-the Phobius web server. Nucleic Acids Res. 2007, 35, W429-W432. [CrossRef] [PubMed]

74. Kearse, M.; Moir, R.; Wilson, A.; Stones-Havas, S.; Cheung, M.; Sturrock, S.; Buxton, S.; Cooper, A.; Markowitz, S.; Duran, C.; et al. Geneious Basic: An integrated and extendable desktop software platform for the organization and analysis of sequence data. Bioinformatics 2012, 28, 1647-1649. [CrossRef] [PubMed]

75. Škodová-Sveráková, I.; Prokopchuk, G.; Peña-Diaz, P.; Záhonová, K.; Moos, M.; Horváth, A.; Šimek, P.; Lukeš, J. Unique dynamics of paramylon storage in the marine euglenozoan Diplonema papillatum. Protist 2020, 171, 125717. [CrossRef]

76. Tashyreva, D.; Prokopchuk, G.; Votýpka, J.; Yabuki, A.; Horák, A.; Lukeš, J. Life cycle, ultrastructure, and phylogeny of new diplonemids and their endosymbiotic bacteria. mBio 2018, 9, e02447-e17. [CrossRef]

77. Yurchenko, V.; Kostygov, A.; Havlová, J.; Grybchuk-Ieremenko, A.; Ševčíková, T.; Lukeš, J.; Ševčík, J.; Votýpka, J. Diversity of trypanosomatids in cockroaches and the description of Herpetomonas tarakana sp. n. J. Eukaryot. Microbiol. 2016, 63, 198-209. [CrossRef]

78. Changmai, P.; Horáková, E.; Long, S.; Černotíková-Stříbrná, E.; McDonald, L.M.; Bontempi, E.J.; Lukeš, J. Both human ferredoxins equally efficiently rescue ferredoxin deficiency in Trypanosoma brucei. Mol. Microbiol. 2013, 89, 135-151. [CrossRef]

79. Hutner, S.H.; Zahalsky, A.C.; Aronson, S.A.; Baker, H.; Frank, O. Culture media for Euglena gracilis. In Methods in Cell Physiology; Prescott, D.M., Ed.; Academic Press: New York, NY, USA; London, UK, 1966; pp. 217-228.

80. Cramer, M.; Myers, J. Growth and photosynthetic characteristics of Euglena gracilis. Arch. Mikrobiol. 1952, 17, 384-402. [CrossRef]

81. Bradford, M.M. A rapid and sensitive method for the quantitation of microgram quantities of protein utilizing the principle of protein-dye binding. Anal. Biochem. 1976, 72, 248-254. [CrossRef]

82. Monteiro, G.; Horta, B.B.; Pimenta, D.C.; Augusto, O.; Netto, L.E. Reduction of 1-Cys peroxiredoxins by ascorbate changes the thiol-specific antioxidant paradigm, revealing another function of vitamin C. Proc. Natl. Acad. Sci. USA 2007, 104, 4886-4891. [CrossRef] 